\title{
Wildland-urban interface (WUI) fire modelling using PHOENIX Rapidfire: A case study in Cavaillon, France
}

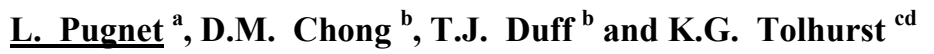 \\ ${ }^{a}$ Institut national de recherche en science et technologies pour l'environnement et l'agriculture (Irstea), UR \\ EMAX, CS 40061, 13182 Aix-en-Provence, France \\ ${ }^{b}$ Department of Forest and Ecosystem Science, Melbourne School of Land and Environment, The University \\ of Melbourne, Burnley, Australia \\ ${ }^{c}$ Department of Forest and Ecosystem Science, Melbourne School of Land and Environment, The University \\ of Melbourne, Creswick, Australia \\ ${ }^{d}$ Bushfire Cooperative Research Centre, East Melbourne, Australia
}

Email: lilian.pugnet@irstea.fr

\begin{abstract}
In parts of the world with Mediterranean type climates, periodic wildfires are part of natural processes. Where such fires impinge on populated areas, there is the potential for significant losses of lives and property. The interface between vegetated areas and human settlements is described as the Wildland Urban Interface (WUI) and is typically where most wildfire losses occur. The threat of fire is becoming an important issue due to increasing populations and the potential for increased fire frequency with climate change. Understanding how wildfires behave in and adjacent to the WUI is important, as it can enable appropriate fire preparedness and response actions to be taken. Dynamic fire spread simulators are widely used to characterise large-scale fires to provide rapid predictions of potential fire spread and impacts, however these scales are generally much greater than those of interest in the WUI. There are currently few options for rapidly characterising fire in the WUI.
\end{abstract}

PHOENIX Rapidfire (PHOENIX) is a wildfire simulator designed to characterise large, fast moving fires in Australia. It is unique in that it incorporates the contribution of firebrand transport and ignition to fire spread. We present a case study where PHOENIX is evaluated as for fine scale WUI fire spread prediction using a fire that occurred in 2012 in Cavaillon, France. This small fire burnt a total of 33 ha in heterogeneous fuels and hilly terrain, which resulted in a variety of impacts within the urban area. A significant feature of this fire was that spotting was observed to be an important part of fire spread; embers were launched from successive ridge tops, carried by winds to ignite fires in adjacent gullies that then ran up subsequent slopes.

PHOENIX requires inputs of fuel, topography and weather. The fuel at Cavaillon was surveyed at a high resolution $(1 \mathrm{~m})$ and defined using the Fire Paradox fuel classification. These classes were converted to equivalent fuel loads ( $\mathrm{t} / \mathrm{ha}$ ) for different fuel strata as used in PHOENIX. The spotting and ember module of PHOENIX was designed for long distance $(>200 \mathrm{~m})$ spotting. Subsequently the spotting model thresholds were manually re-calibrated to provide a comparable spotting pattern to those observed at Cavaillon. Weather inputs were sourced from a nearby automatic weather station. Simulations of fire spread were run at resolutions of $5,10,15,20 \mathrm{~m}$.

Observations of the Cavaillon fire supplied by the local fire brigade were used to reconstruct the actual fire progression. A simulation of the fire using the best data available was compared to the observed perimeter at 18:00. PHOENIX was effective in predicting spread in the WUI, however testing against other fire events is required before its widespread use.

The simulation of small scale spotting appears to be a necessary step in the simulation of such fires where it is a key spread mechanism. In addition modelled ember densities can be used to predict asset impacts, which can supplement standard intensity threshold approaches. The ability to evaluate fire spread characteristics at the WUI scale would provide significant opportunities to estimate impact risk, reconstruct fire behaviour, undertake vulnerability modelling, evaluate fire mitigation strategies and assist suppression planning. The results of our investigation indicate that further research in this area is warranted.

Keywords: Fire behaviour, fuel types, PHOENIX Rapidfire, wildfire reconstruction, wildland-urban interface (WUI). 
Pugnet et al., Wildland-Urban Interface (WUI) fire modeling using PHOENIX Rapidfire: A case study in Cavaillon, France

\section{INTRODUCTION}

Wildfires are a natural occurrence in parts of the world with Mediterranean type climates. When they occur in populated areas, they have the potential to cause death, human injury and substantial economic losses. Southern France is one area of particular vulnerability due to the large areas of fragmented, fire prone forest intermixed with urban developments. These areas, described as the Wildland-Urban Interface (WUI) (Lampin et al., 2009), are typically where the greatest wildfire losses occur due to the combination of forest fuels, high densities of human habitation and increased likelihood of anthropogenic fire ignitions.

The vegetation in Mediterranean areas is adapted to promote periodic fire; as a result it is inevitable that wildfires that impact the WUI will occur. As the complete prevention of all fires is an unachievable goal for land managers, management focuses on minimising losses of human lives and asset impacts (including dwellings, infrastructure, carbon, ecological and watershed). Fire impacts are managed in the WUI through preparedness actions (such as fuel modification and house design) and suppression (active fighting of fires when they occur). In order to do this effectively it is necessary to have an understanding of the fire behaviour dynamics within the WUI, including likely rates of spread, flame heights, firebrand characteristics and intensity. Characterising fire in forested areas is a challenging process due to the interaction of inherently complex factors that drive fire spread; fuel, weather and topography. WUI areas are a particular challenge as the fuels are typically highly heterogeneous, varying at small scales (particularly due to wildland fuels intermingled with houses, gardens and non-flammable features such as roads) and there is generally a high level of human interaction with fire spread (in the form of suppression). Despite this, there is growing pressure to develop decision support tools that can characterise fire in the WUI due to the concentration of vulnerable assets and the need to know what the likely threat mechanisms are (flame contact, radiation or embers) and how these threats can be reduced.

Dynamic fire spread models are tools that have been developed to characterise the spread of fires at large scales. While there is great variety in the form and complexity of models developed, comparatively simple models that can provide rapid predictions of fire behaviour and progression are becoming rapidly adopted for fire management (e.g. FARSITE (Finney, 2004), PHOENIX Rapidfire (Tolhurst et al., 2008) and Prometheus (Tymstra et al., 2010)). Timely predictions enable the progression of fires to be anticipated while they are occurring, enabling warnings to be given and suppression activities to be planned. Post-event, these models can be used to 'reconstruct' fire progression to provide an indication of transient, difficult to observe elements of fire behaviour including spatially specific rates of spread, flame heights, and firebrand characteristics. The complexity of WUI, with its homogenous and discontinuous fuels, has limited the development of fire models particularly designed for rapid fire prediction at wildland interface. Rapid operational fire models typically consider the landscape at large scales (typically $>100 \mathrm{~m}^{2}$ data resolution), much larger that the scales of heterogeneity within WUI environments (considered at scales of $<20 \mathrm{~m}^{2}$ ). While there have been WUI fire characterisation models developed, they have been highly complex, requiring substantial detail in inputs and consuming significant processing power and time (Mell et al., 2010). There is a need for models that are able to provide predictions of fire spread/behaviour in the WUI at operationally useful time scales (Rehm and Mell, 2009). However this is an impasse where models designed for fire simulation at fine scales appropriate for the WUI require long processing times and models developed for rapid computation are generally focused on large scale fires.

There is a need for fire models that can characterise fire spread and asset impacts for WUI fires. In this study, we evaluate the potential of the Australian model, PHOENIX Rapidfire (PHOENIX), for the characterisation of fire behaviour in the Mediterranean WUI using a case study fire that occurred near Cavaillon, South-Eastern France in 2012. PHOENIX is a dynamic, mechanistic, spatially continuous, empirical fire characterization computational model. Fire spread is computed using Huygen's wavelet principle (Anderson et al., 1982) and represents the fire front as a series of points forming a continuous line. Observations of the Cavaillon fire indicate that firebrand transport was an important mechanism for the fire to travel across discontinuous fuels. PHOENIX contains a deterministic firebrand transport and ignition module, however it is calibrated for large scale fire spread. Consequently the evaluation required three steps (i) harmonising Mediterranean fuel types with equivalent Australian fuel classification, (ii) adjusting the firebrand module to match observations, and (iii) adjustment of the model to process high resolution inputs. Model performance was evaluated by comparing predicted fire perimeters against observed perimeters using an area difference index (ADI). 
Pugnet et al., Wildland-Urban Interface (WUI) fire modeling using PHOENIX Rapidfire: A case study in Cavaillon, France

\section{METHODS}

\section{1. $\quad$ Fire case study}

On the 21 July 2012 a fire occurred near Cavaillon in southern France that burnt at total area of 33 ha. The fire occurred in hilly terrain and burned through a heterogeneous and discontinuous mix of fuels. Observations of the fire indicated that wind-carried firebrands were an important mechanism for fire spread during the initial stages of the fire, with embers launched from ridges initiating new fires in adjacent gullies. Suppression activity was undertaken during the fire, with over 300 firefighters and 30 aerial drops. No houses were lost; however there was some asset damage. The fire occurred on the southern side of "Colline St Jacques" and was driven in a south easterly direction by wind. It progressed across rugged terrain; with spread traversing across a series of ridges and gullies aligned perpendicularly to primary spread direction. Fuel types were characteristic of the limestone Provence, consisting of low $(<3 \mathrm{~m})$ dense garrigue vegetation. The area had been previously burnt in 2006. The fire was driven by the relatively cool but strong Mistral winds of southern France, with temperatures around $24^{\circ} \mathrm{C}$, relative humidity approximately $30 \%$ and wind speeds averaging over $44 \mathrm{~km} / \mathrm{h}$.

The cause of the fire was arson, with ignition occurring at 13:30 on the edge of a road closed to motor vehicles $\left(43^{\circ} 50^{\prime} 21,624^{\prime \prime} \mathrm{N}, 5^{\circ} 1^{\prime} 11,784 " \mathrm{E}\right)$. There was a rapid suppression response, with the first resources arriving at 13:45. Approximately one hectare was burnt before the perimeter of the initial fire was contained primarily by retardant drops from aircraft. However wind blown embers ignited a spotfire outside the primary fire perimeter at the base of a gully (Figure 1). The new fire accelerated rapidly due to the combined effect of strong winds and slope and a decrease in fuel height (resulting in increased wind exposure of flames). The direction of the slope contributed to a rapid increase in fire width, which allowed the fire to burn into taller, heavy fuels that didn't burn in 2006. As a consequence, there was a rapid increase in fire intensity and spread rates. The fire exhibited spread rapidly with the wind in a southeast direction, crossing gullies via spotting. Observations of the firefighters on the ground indicate that there were regular ignitions of spotfires 40 to $50 \mathrm{~m}$ ahead of the fire perimeter. Fire behaviour moderated towards the end of the day, and the fire was contained at 19:30.

The final burnt area was mapped in the field, using a Global Positioning System (GPS). In addition, observations of witnesses during the fire were used to reconstruct isochrones of fire progression (Figure 1), enabling the perimeter of the fire to be mapped at 7 points in time. While the final perimeter is mapped with confidence $(\sim 1 \mathrm{~m})$, there is no metadata available to describe the spatial or temporal accuracy of the reconstructed perimeters.

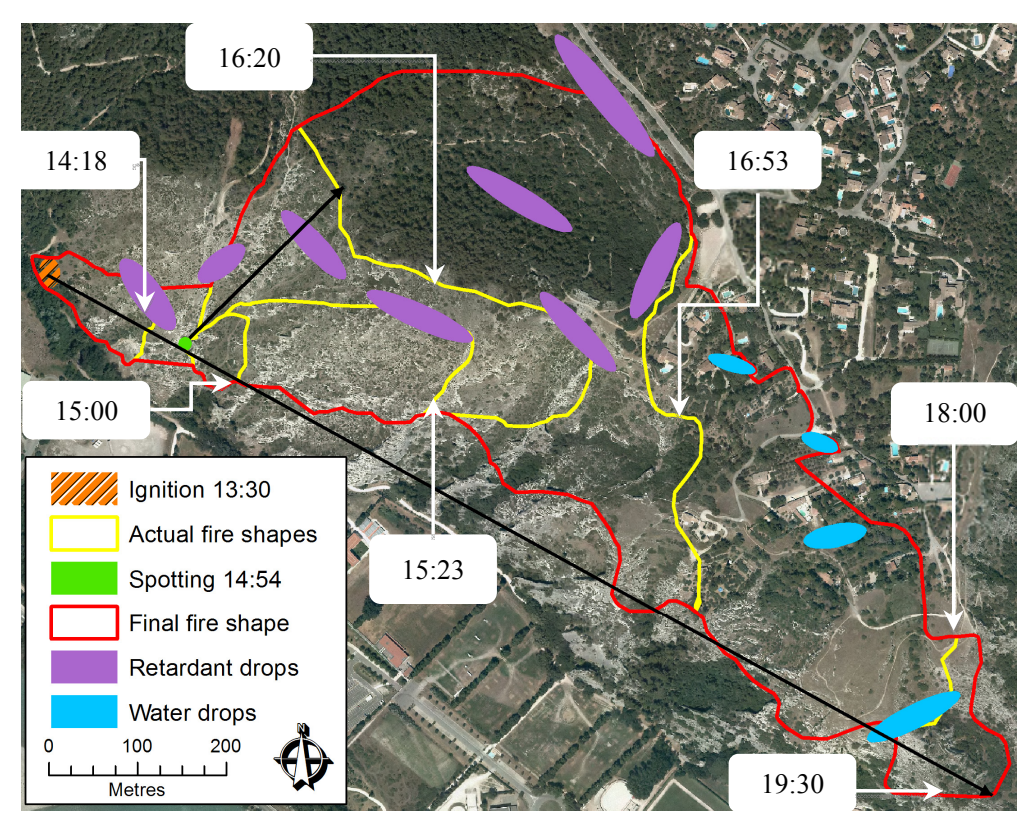

Figure 1. Map depicting suppression efforts and the different shapes of Cavaillon fire, from ignition at 13:30 to containment at 19:30. The dominant directions of fire spread are represented in black. 
Pugnet et al., Wildland-Urban Interface (WUI) fire modeling using PHOENIX Rapidfire: A case study in Cavaillon, France

\subsection{PHOENIX data requirements}

This simulation of fire spread with PHOENIX requires inputs of fuel, suppression, topography and weather.

Fuel

PHOENIX processes fuel as mapped classes derived from vegetation types. Each vegetation type has a corresponding table of fuel characteristics based on the fuel load in various strata as defined using standard Australian fuel descriptors (Hines et al., 2010). In France, an alternative classification is used, so it was necessary to develop a system for conversion.

In the fire affected area, pre-fire high resolution $(20 \mathrm{~cm})$ aerial photographs and post fire field surveys were used to map a range of vegetation characteristics (cover fraction, height by strata, crown base height, main species). These were matched with nine corresponding fuel complexes as defined under the Fire Paradox project (Jappiot et al., 2009). Mapping was undertaken using GPS-equipped laptop and ArcGIS 10, and the final map resolution is $1 \mathrm{~m}$. To represent forest stands where surface fuel reduction had been conducted (due to the 2006 fire), a new fuel type of "High and closed forest without understorey" was derived from the "High and closed forest stands" fuel type. Additional fuel types for "Grassland" and "Hedge" were also added based on field survey data. In total, twelve fuel types were used to describe the affected area representing six discrete vegetation types (Table 1).

Fuels were originally stratified into 3 height classes $<1 \mathrm{~m}, 1-3 \mathrm{~m}$ and $>3 \mathrm{~m}$. Fuel bulk density values for each vegetation type were obtained from the available literature (Lampin et al., 2004; Ganteaume et al., 2007; Jappiot et al., 2009; Ganteaume et al., 2013) and used to determine the fuel load at each stratum using equation (1):

$$
F L=\frac{C F \times(H-C B H) \times B D}{10}
$$

- $\quad$ FL: fuel load ( $\mathrm{t} / \mathrm{ha})$

- CF: cover fraction (\%)

- $\quad \mathbf{H}$ : height (m)

- CBH: crown base height (m)

- BD: bulk density $\left(\mathrm{kg} / \mathrm{m}^{3}\right)$

Table 1. Fuel type characterization. Min and max fuel loads (t/ha) are shown for each stratum.

\begin{tabular}{|c|l|c|c|c|c|}
\hline Types & \multicolumn{1}{|c|}{ Fuel Complexes } & Fuel load $<\mathbf{1 ~ m}$ & Fuel load 1-3 m & Fuel load $>\mathbf{3 ~ m}$ & Total Fuel load \\
\hline A & High and closed forest stands & 5.5 & {$[0-4]$} & {$[7.2-8.4]$} & {$[13.9-17.9]$} \\
\hline Ad & Type A without understorey & {$[0-0.6]$} & {$[0-3]$} & {$[9-9.6]$} & {$[9.6-12.6]$} \\
\hline B & Low and closed forest stands & 4.7 & 8.6 & 1.3 & 14.6 \\
\hline C & High garrigue & {$[0.4-1]$} & {$[2.3-11.3]$} & 0 & {$[3-12]$} \\
\hline D & Low garrigue & 8.7 & 4 & 0 & 12.7 \\
\hline E & Open shrub-cleared forest & 1.4 & 2.3 & 4.5 & 8,2 \\
\hline F & Very low and closed forest stands & 7.5 & 13.9 & 4.5 & 29.5 \\
\hline G & Dense and medium height forest stands & 3.8 & 7.8 & 1.4 & 13 \\
\hline H & High and sparse forest stands & 0.3 & 4.6 & 3.1 & 8 \\
\hline I & H with dense understorey & 9.1 & 6.3 & 6.1 & 21.4 \\
\hline J & Grassland & 1.1 & 0 & 0 & 1.1 \\
\hline K & Hedge & {$[7.1-132.9]$} & {$[0-664.7]$} & {$[0-398.8]$} & {$[7.6-797.6]$} \\
\hline
\end{tabular}

PHOENIX dynamically incorporates fuel based on simulated flame height. Due to the low vegetation heights and the high-observed flame heights $(>2 \mathrm{~m})$, it was assumed that both the $1 \mathrm{~m}$ and 1-3 $\mathrm{m}$ fuels would be available to burn. The $>3 \mathrm{~m}$ stratum is considered by PHOENIX as crown fuels, and is not included in spread calculations. PHOENIX uses estimates of eucalypt bark fuel load (t/ha) in the calculation of quantity of firebrand material available to be lofted. Recent studies (Ganteaume et al., 2011; Manzello et al., 2007) identified pine cones, bark scales, acorns, leaves, twigs and globular cones as sources of firebrands in the Mediterranean basin. These are typically of sizes consistent with the $10 \mathrm{hr}$ (Anderson, 1982) fuel size class (diameters between 0.64 and $2.54 \mathrm{~cm}$.) so estimates of the $10 \mathrm{hr}$ fuel load (average proportion of $10 \mathrm{hr}$ fuel load for the same fuel types (Lampin et al., 2004)) were used to determine an equivalent eucalypt bark load. The fuel class conversion has not been independently verified with field measurements. Linear fuel disruptions such as roads, rivers and firebreaks can be included as PHOENIX data inputs, however these are assumed to be captured in the supplied $1 \mathrm{~m}$ fuel mapping. 
Pugnet et al., Wildland-Urban Interface (WUI) fire modeling using PHOENIX Rapidfire: A case study in Cavaillon, France

\section{Topography}

A $25 \mathrm{~m}$ digital elevation model (DEM) was sourced from the French National Geographic Institute. This was used to derive a $25 \mathrm{~m}$ 'terrain affected' wind adjustment layer (in speed and direction) using the conservation of mass model 'Wind Ninja' (Forthofer, 2007). Other DEM derived parameters (such as slope and aspect) are calculated "on the fly" by PHOENIX.

\section{Weather}

An automatic weather station was situated near the fire ignition point $\left(43^{\circ} 50^{\prime} \mathrm{N}, 5^{\circ} 03^{\prime} \mathrm{E}\right)$ located on the outskirts of Cavaillon, some $2.5 \mathrm{~km}$ east of the ignition point in a flat urban area at an elevation of $75 \mathrm{~m}$. Given the small elevation differences between the weather station, the ignition location elevation $(69 \mathrm{~m})$ and maximum elevation reached by the fire (182 $\mathrm{m})$, it was assumed that differences in temperature and humidity would not be material, so no adjustments were made.

\subsection{PHOENIX simulation}

PHOENIX data are typically standardised to grid resolutions over $100 \mathrm{~m}$, each cell containing the weighted average of any input datasets, regardless of scale. To properly consider the WUI information, it is necessary to process it at higher resolutions. Computations of spread are scale independent, however the internal fire spread model is based on the McArthur model (McArthur, 1967), which has not been validated at fine scales. To evaluate the influence of simulation data resolution to predictive performance, PHOENIX was used to simulate the fire at grid resolution of $5,10,15$ and $20 \mathrm{~m}$.

The firebrand transport and ignition model of PHOENIX is designed to emulate long distance 'Eucalyptstyle' spotting, from $200 \mathrm{~m}$ to $25 \mathrm{~km}$. However, spotting distances observed in the case study were in the order of $10-50 \mathrm{~m}$ due to heavier and less aerodynamic firebrands. To capture this in the simulation, parameters in the spotting submodel were manually calibrated to provide a comparable spotting pattern to those observed. The spotfire algorithm is scale dependant, so modification required an adjustment of the spotfire ignition grid resolution from $200 \mathrm{~m}$ to $5 \mathrm{~m}$ and the spotfire density ignition threshold from 1 to 0.01 spotfire $/ \mathrm{m}^{2}$. The maximum time an ember can stay aloft was reduced from 25 minutes to 1 minute to reflect the heavier and less aerodynmic nature of the local spotting material. In addition, spotting in PHOENIX is more strongly driven by convection rather than surface winds, and consequently uses non-terrain affected wind for ember transport. Due to the relatively small scales of observed spotting, in this study the terrain affected winds were used as transport vectors. As the reconstructed fire perimeters indicate suppression activities had minimal effect in stopping the spread, suppression was not simulated.

For evaluation purposes, perimeters were compared with the perimeter observed at 18:00 to avoid limitations due to issues with data availability. The final 19:30 perimeter was only 4\% larger than 18:00 perimeter. Model performance was evaluated using an Area Difference Index; calculated as the sum of the incorrectly estimated area (underprediction and overprediction) divided by the correctly predicted area. A range of ADIs was generated running 4 simulations at different grid resolution.

\section{RESULTS}

With the spotting model calibrated to emulate the maximum spotting distances observed in this fire, reasonable predictions were achieved across all 4 simulations with an average ADI of 0.77 and standard deviation of 0.07. The worst case has an ADI of 0.842 , and was for a grid resolution of $20 \mathrm{~m}$ (Figure $2 \mathrm{~b}$ ). The best result has an ADI equal to 0.679, and was for a grid resolution of $10 \mathrm{~m}$ (Figure 2b).
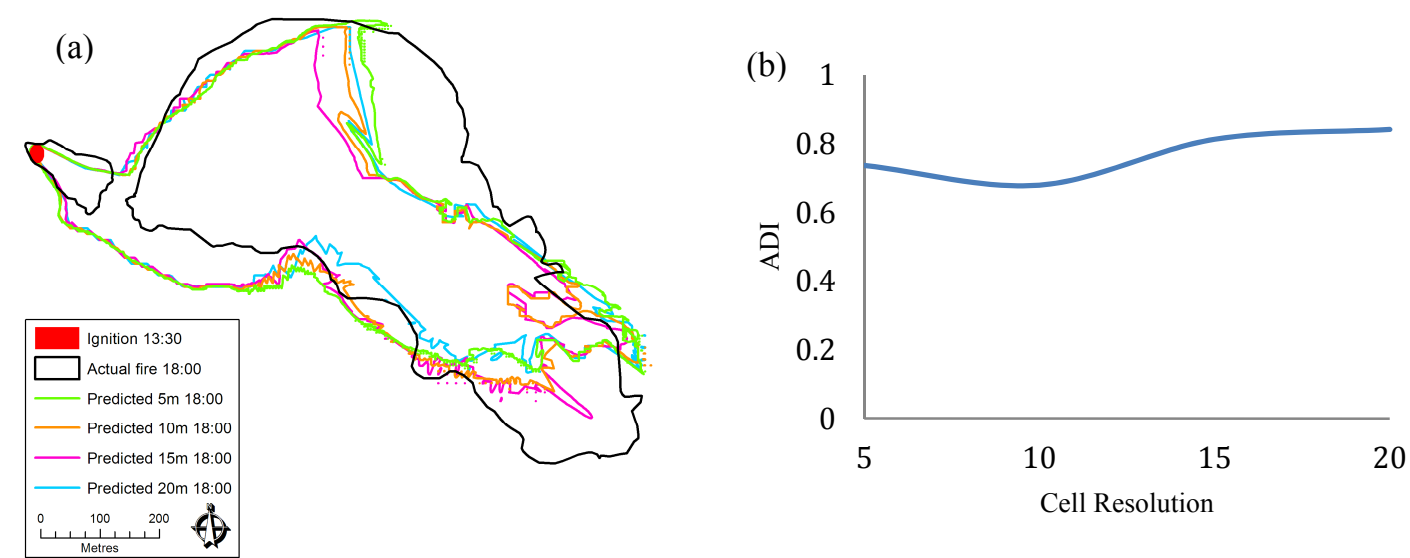

Figure 1. Maps showing the perimeter of the Cavaillon fire at 18:00, and the 4 simulated fire shapes (a). ADI sensitivity analysis for cell resolution variation (b). 
Pugnet et al., Wildland-Urban Interface (WUI) fire modeling using PHOENIX Rapidfire: A case study in Cavaillon, France

There was no consistent bias observed resulting from varying in cell resolution. Although there was some underprediction on the upper right side of the fire (Figure 2a), the 4 predicted perimeters are considered a good match; ADI $=0$ representing a perfect fit and values below 1 considered a good fit.

\section{DISCUSSION AND CONCLUSIONS}

With the conversion of Mediterranean fuels to suitable formats, PHOENIX was able to achieve robust predictions of fire spread in Cavaillon, however the fire shape was not perfectly characterised. Inaccurate model inputs may contribute to this; the observed winds at the weather station were consistently recorded at $310^{\circ}$ from 8 am to $8 \mathrm{pm}$. Consistency may be a feature of the Mistral winds; however it can also be an indication of issues with recording equipment. The fire occurred on the southern slope of Colline St Jacques, however winds were blowing from the North West. Consequently, the fire is in the lee of the mountain so there are likely to be strong terrain/wind interactions. This may result in different wind conditions at the fireground than those at the weather station. While the terrain affected wind computations may account for some of the local effects, computations were based on conservation of mass and are not able to account for turbulence, wind deflection or complex channelling. The simulations underestimate the channelling process, it appears that a better consideration of wind local effects might improve the goodness of fit.

While many European and American fire models do not explicitly incorporate spotting into fire progression, observations of the Cavaillon fire indicate that spotting remains an important process to fire spread, albeit at much smaller scales than in Australia. Once calibrated, the PHOENIX spotting model was able to emulate the fire's ridge top launch of embers that allowed non-flammable gullies to be breached, followed by rapid uphill runs that lead to subsequent ember launches. Without the inclusion of firebrands, the simulation would have been stopped at the first gully that the fire encountered after ignition. Ember transport was critical to the simulation of the Cavaillon fire. As embers also play a key role in igniting buildings and other assets (Leonard and Blanchi, 2005), fire simulations that can provide a spatially explicit index of ember attack may be valuable for evaluating WUI impact risk.

While PHOENIX created a reasonable prediction of the Cavaillon fire, it must be recognised that the underlying spread functions used in the model are based on an empirical fit to experimental fires that were at least $50 \mathrm{~m}$ wide and were assumed to be burning at equilibrium rates (McArthur, 1967; Noble et al., 1980). When simulating at scales smaller than this, there is the potential that some outcomes may be an artefact of prediction outside the development range of the model. Such artefacts were clearly present when carrying out test PHOENIX simulations at very fine scales $(<5 \mathrm{~m})$, but may also be a source of prediction error in the case study example. WUI fire characterisation was evaluated here with a single case study, due to the many sources of uncertainty in fire simulation, further replication would be required before confident predictions can be made. In addition, the functions underlying forest fire spread in PHOENIX were calibrated in eucalypt forests, the difference in the properties of the garrigue fuels (in terms of structure, moisture content and calorific value) may be an additional source of error.

The successful simulation of the Cavaillon fire with the large-scale fire model, PHOENIX Rapidfire, indicates that such models may have value in characterising fire behaviour in WUI in the Mediterranean region. Rapid and accurate WUI fire models would aid operational fire suppression, enable risks to be evaluated and fires to be reconstructed post-event. As there are limited decision support tools for managing fire in the WUI, further investigation into the application of fire characterisation models at high resolutions is warranted.

\section{ACKNOWLEDGMENTS}

We would like to recognise the in-kind contribution of data and support from the Cavaillon Service of Fire and Rescue. We gratefully acknowledge the support and cooperation of the Commonwealth Scientific and Industrial Research Organisation, Ecosystem Sciences research division, Victoria.

\section{REFERENCES}

Anderson, H. (1982). USDA Forest Service, Intermountain Forest and Range Experiment Station. General Technical Report INT-122, 22 pp.

Anderson, D. H., Catchpole, E. A., de Mestre, N. J. and Parkes, T. (1982). Modelling the spread of grass fires. Journal of Australian Mathematics Society, Series B, 23, 451-466. 
Pugnet et al., Wildland-Urban Interface (WUI) fire modeling using PHOENIX Rapidfire: A case study in Cavaillon, France

Finney, M. A. (2004). FARSITE: Fire area simulator-model development and evaluation. In R. M. R. Station (Ed.), Research Paper. Missoula, MT: Rocky Mountain Reseach Station, Forest Service, U.S. Department of Agriculture.

Forthofer, J. M. (2007). MA Thesis: Modeling wind in complex terrain for use in fire spread prediction. Colorado State University, Fort Collins, Colorado.

Ganteaume, A., Jappiot, M., Lampin C., Guijarro, M. and Hernando, C. (2013). Flammability of some ornamental species in Wildland-Urban Interfaces in Southestern France: Laboratory assessment at particle level. Environmental Management. DOI 10.1007/s00267-013-0067-z.

Ganteaume, A., Guijarro, M., Jappiot, M., Hernando, C., Lampin, C., Pérez-Gorostiaga, P. and Vega, J.A. (2011). Laboratory characterization of firebrands involved in spot fires. Annals of Forest Science, 68, 531-541.

Ganteaume, A., Jappiot, M., Abdelmoula, K., Allgöwer, B., Borgniet, L., Curt, T., Ghosn, D., Gitas, I., Kazakis, G., Koetz, B., Lampin, C., Mårell, A., Morge, D., Morsdorf, F., Rigolot, E., Sesbou, A., Vega, J.A. and Vigy, O. (2007). Georeferenced database of representative sites including ecological data. Deliverable D.3.4-1 of the Integrated project "Fire Paradox", Project no. FP6- 018505, European Commission.

Hines, F., Tolhurst, K., G., Wilson, A. G. and McCarthy, G. J. (2010). Overall fuel hazard assessment guide, 4th Edition. In Department of Sustainability and Environment (Ed.), Research Report series. Melbourne: Department of Sustainability and Environment Victoria, Melbourne.

Jappiot, M., Alexandrian, D., Benjelloun, H., Cassagne, N., Dupuy, J.L., Ganteaume, A., Hachmi, M., Lampin-Maillet, C., Pimont, F., Rigolot, E., Rouch, L., Sesbou, A., Abdelmoula, K., Allgöwer, B., Borgniet, L., Curt, T., Defossé, G., Ghosn, D., Gitas, I., Jimenez, E., Kazakis, G., Koetz, B., Long, M., Louis, S., Machrouh, A., Mårell, A., Morge, D., Moro, C., Morsdorf, F., Vega, J.A. and Wellani, W. (2009). Guide for characterizing fuels and assessing fuel type's combustibility. Deliverable D.3.4-5 of the Integrated project "Fire Paradox", Project no. FP6-018505, European Commission.

Lampin, C., Jappiot, M., Long, M., Morge, D. and Ferrier, J.P. (2009). Characterization and mapping of dwelling types for forest fire prevention. Environment and Urban Systems, 33, 224-232.

Lampin, C., Chandioux O., Paulet V. and Jappiot, M. (2004). Typologie de la végétation combustible dans les interfaces agriculture-forêt-urbain. Rapport final, Conseil Régional.

Leonard, J. and Blanchi, R. (2005). Investigation of bushfire attack mechanisms involved in house loss in the ACT Bushfire 2003. Highett, Vic., CSIRO Manufacturing \& Infrastructure Technology. Bushfire CRC report.

Manzello, S.L., Maranghides, A. and Mell, W.E. (2007). Firebrand generation from burning vegetation. International Journal of Wildland Fire, 16, 458-462.

McArthur, A. G. (1967). Fire behaviour in Eucalypt forests. In. Canberra, Australia: Forestry and Timber Bureau, Department of National Development.

Mell, W. E., Manzello, S. L., Maranghides, A., Butry, D. and Rehm, R. G. (2010). The wildland-urban interface fire problem - current approaches and research needs. International Journal of Wildland Fire, 19, 238-251.

Noble, I. R., Gill, A. M. and Bary, G. A. V. (1980). McArthur's fire-danger meters expressed as equations. Austral Ecology, 5, 201-203.

Rehm, R. G., and Mell, W. (2009). A simple model for wind effects of burning structures and topography on wildland-urban interface surface-fire propagation. International Journal of Wildland Fire, 18, 290-301.

Tolhurst, K. G., Shields, B. and Chong, D. (2008). PHOENIX: development and application of a bushfire risk management tool. Australian Journal of Emergency Management, 23(4), 47-54.

Tymstra, C., Bryce, R. W., Wotton, B. M., Taylor, S. W. and Armitage, O. B. (2010). Development and structure of Prometheus: the Canadian wildland fire growth simulation model. In Information Report. Edmonton, Alberta, Canada: Canadian Forest Service. 